\title{
Effect of moisture on the bending properties of thermally modified beech and spruce
}

\author{
Martin Arnold
}

Received: 18 May 2009/ Accepted: 13 October 2009/Published online: 27 October 2009

(C) Springer Science+Business Media, LLC 2009

\begin{abstract}
For appropriate and successful applications of thermally modified wood, a detailed knowledge of its distinct properties is essential. A thermal modification leads to structural and chemical changes in the wood constituents, which may significantly alter the material properties as compared to untreated solid wood. As contribution to a comprehensive material characterisation, moisture-mechanical property relationships were studied for selected bending properties of untreated and thermally modified beech and spruce. Static bending tests were conducted on small clear specimens at three treatment and five moisture levels. Bending strength at standard (dry) climate conditions was reduced by the thermal modification, while stiffness tended to show some increase. Furthermore, both properties decreased with increasing moisture content in untreated as well as thermally modified wood. However, because of the lower moisture sensitivity of thermally modified wood, the moisture dependence of its bending properties was considerably reduced. Therefore, in moist environments, equal or even better stiffness and strength values may be expected for thermally modified wood as compared to untreated solid wood. On the other hand, the changed fracture behaviour of thermally modified wood related to its increased brittleness, which was present also in wet conditions, has to be taken into account for potential structural applications.
\end{abstract}

M. Arnold ( $\square)$

Empa, Swiss Federal Laboratories for Materials Testing and Research, Wood Laboratory, 8600 Dübendorf, Switzerland

e-mail: martin.arnold@empa.ch

\section{Introduction}

As a biological material, wood shows some intrinsic properties often considered disadvantageous for technical purposes (e.g. high variability, limited durability). To improve some of these 'weak' properties, a wide variety of treatments and modification techniques have been developed over the years. In contrast to the classical chemical wood preservation, which focuses mainly on durability, wood modification additionally aims to improve selected physical and mechanical properties. Roughly, the various techniques can be classified into chemical or thermal, surface or bulk, and cell wall altering or lumen filling modification methods $[1,2]$. Thermal wood modification is a long-known technology (see [2-5] and literature cited therein), but it has received increased attention in the last decade particularly in Europe, leading to an intensified industrial production and commercialisation $[2,6,7]$. As a result, thermally modified timber (TMT) is increasingly used as an alternative wood based material for special applications.

However, a thermal modification leads to structural and chemical changes in the wood constituents, which may significantly alter the material properties as compared to untreated solid wood. TMT is therefore regarded in many aspects as a separate class of wood based materials with distinct properties. As reviewed in [2, 4], for most thermal modification processes improvements in dimensional stability and durability have been reported, while strength properties generally decrease. The extent of the property changes will vary depending on the type of process, its specific conditions and the wood species.

For appropriate and successful applications of TMT, its particular properties have to be known in detail and carefully considered. Although basic experimental work was 
done much earlier, recent research has facilitated a considerable additional knowledge of the physical and mechanical properties of TMT [2, 4, 7-10], but various specific aspects typical for solid wood have still to be explored [11, 12]. Additionally, most of the prior work was done on softwoods, and therefore, knowledge is still somewhat limited regarding hardwoods. One so far insufficiently considered topic is the effect of moisture on the mechanical properties, which has been extensively studied for solid [13-15] and chemically modified wood [16], but is largely unknown for TMT.

Moisture effects in solid wood

Since wood is a highly hygroscopic material, most of its properties are considerably influenced by the moisture content (MC). Particularly regarding the mechanical properties and the use of wood in structural applications, $\mathrm{MC}$ is known to be one of the major influencing factors [17-21]. Below the fibre saturation point (FSP), an increase of MC will generally lead to a decrease in mechanical properties, while above FSP moisture effects are usually negligible. At very low MC, some mechanical properties may decrease again after reaching a maximum value [15]. The various mechanical properties have a different sensitivity to changes in MC, with strength properties more sensitive than stiffness properties and static properties more sensitive than dynamic properties [20, 22]. Regarding the type of stress, compression parallel to grain is strongly affected by MC, while MC has less effect on tensile strength and as a consequence, an intermediate influence on bending properties [15]. Finally, the effects of MC are more distinct with small clear specimens than with structural timber, where again the higher grades are more sensitive to MC differences than low quality timber [15].

\section{Moisture effects in TMT}

Because a thermal modification reduces the hygroscopicity of wood [2, 4], a lower moisture sensitivity may be expected for TMT [23-25]. Regarding moisture effects on mechanical properties, the reduced moisture sensitivity of TMT could compensate partially for the general reduction of strength properties by the thermal modification [16]. This would be a particular advantage for a possible use of TMT in structural applications, where expected moisture conditions in service have to be considered and design values adapted accordingly.

While many studies have dealt with the mechanical properties of TMT at standard climate conditions [26-30], relatively little information is available regarding the moisture dependent behaviour [31-34]. Only very few studies have specifically focused on the importance of moisture effects on the mechanical properties of TMT $[35,36]$. Overall, these studies suggest a reduced moisture effect on the mechanical properties of TMT. However, their limited scope and the often restricted moisture range do not allow general conclusions.

\section{Objectives}

The presented work is part of a series of experiments to assess the basic physical and mechanical properties of TMT. The objective of this particular study was to explore the effects of the wood MC on the mechanical properties of TMT. As an example, static bending was selected because this is a frequent load situation in wood constructions and because bending properties are widely used in grading and design standards as reference values. Bending tests were conducted with two wood species at three treatment and five moisture levels.

\section{Experimental}

\section{Material}

The test material consisted of thermally modified and untreated control specimens of beech (Fagus sylvatica) and spruce (Picea abies). A proprietary industrial thermal modification process [37] with two modification levels was used (Table 1). The high temperature phase of the process was performed in a gas atmosphere under exclusion of oxygen. To closely reflect real production conditions, thermal modification was done on whole boards with test specimens cut subsequently and not on pre-cut specimens as done in most earlier studies [26, 27, 30-32, 36]. Prior to the thermal modification, a section of each board was cut to be used for control specimens. Thus, modified and control specimens were prepared from the same source of raw material.

To assess 'pure' material properties and to exclude the effects of structural defects, small clear specimens were used. Specimens were machined after conditioning at $20{ }^{\circ} \mathrm{C} / 65 \%$ relative humidity ( $\left.\mathrm{RH}\right)$ to a nominal crosssection of $20 \times 20 \mathrm{~mm}^{2}$ and a length of $360 \mathrm{~mm}$. Care was taken to achieve a parallel-perpendicular orientation of the growth rings within the specimen cross-section. After

Table 1 Treatments/thermal modification levels (HT)

\begin{tabular}{ll}
\hline HT & Description \\
\hline T0 & Untreated controls (kiln-dried, max. temperature $\left.65{ }^{\circ} \mathrm{C}\right)$ \\
T1 & 'Mild' heat treatment (max. temperature $180{ }^{\circ} \mathrm{C}$ for $4 \mathrm{~h}$ ) \\
T2 & 'Intense' heat treatment (max. temperature $220{ }^{\circ} \mathrm{C}$ for $4 \mathrm{~h}$ ) \\
\hline
\end{tabular}


Table 2 Moisture levels (ML)

\begin{tabular}{|c|c|c|c|}
\hline ML & $\begin{array}{l}\text { Moisture } \\
\text { condition }\end{array}$ & $\begin{array}{l}\text { Relative } \\
\text { humidity RH (\%) }\end{array}$ & $\begin{array}{l}\text { Conditioning } \\
\left(\geq 14 \text { days, } 20{ }^{\circ} \mathrm{C}\right)\end{array}$ \\
\hline ML1 & Dry & 35 & Storage in climate chamber \\
\hline ML2 & Standard & 65 & Storage in climate chamber \\
\hline ML3 & Humid & 85 & Storage in climate chamber \\
\hline ML4 & At FSP & 98 & Storage in saturated air \\
\hline ML5 & Above FSP & - & $\begin{array}{l}\text { Water soaking by submersion } \\
\text { in deionised water }\end{array}$ \\
\hline
\end{tabular}

FSP fibre saturation point

machining, specimens were conditioned to equilibrium at five moisture levels according to Table 2, covering a wide moisture range as observed in real use conditions.

To achieve homogenous and comparable specimen sets for each of the three treatment and five moisture levels per wood species, the specimens from the different boards were distributed uniformly over the five moisture levels. For each treatment and moisture level, a set of 15 replicate specimens was prepared amounting to a total of 450 bending sticks.

\section{Bending tests}

Bending properties were assessed by a three-point static bending test according to DIN 52186 [38] on a universal testing machine $(300 \mathrm{~mm}$ span). To reach failure within $90 \pm 30 \mathrm{~s}$, the crosshead speed was adjusted between $1,600 \mathrm{~N} / \mathrm{min}$ for untreated beech controls and $400 \mathrm{~N} / \mathrm{min}$ for spruce specimens with modification level $\mathrm{T} 2$ at moisture level ML5. Bending deflection was measured by crosshead movement. Some few replicate specimens were excluded from further data analysis because of structural imperfections and/or abnormal bending behaviour.

To address different aspects of bending behaviour, three bending properties were derived from the collected loaddeflection data: (1) modulus of elasticity (MOE, in N/mm²) served as measure of the material elasticity, (2) modulus of rupture (MOR, in $\mathrm{N} / \mathrm{mm}^{2}$ ) represented the ultimate bending strength and (3) deflection at maximum load (DFMAX, in $\mathrm{mm}$, measured over total span) was used as an indicator for toughness and fracture behaviour (i.e. brittleness). Specimen cross-sections were measured at test conditions (i.e. at different swelling states) and the calculation of the bending properties was based on these values.

After testing, oven-dry density (OD) and MC were determined as bulk properties of the whole bending sticks according to DIN 52182 [39] and DIN 52183 [40], respectively. To further characterise the fracture behaviour, small splinters were cut from the tension side of the fracture surfaces of selected broken sticks, sputtered with platinum and examined in a high-resolution field-emission scanning electron microscope (FE-SEM) regarding the morphology of the transverse-fracture surfaces [41].

\section{Results}

Changes in density and moisture content

Oven-dry density for the two wood species at the three treatment levels is reported in Table 3. Resulting from the applied systematic specimen allocation, OD in the five moisture levels per species-treatment sample was very similar (data not shown). As a general measure of material degradation by the thermal modification, the change of OD compared to untreated controls was calculated (see ratios T1/T0 and T2/T0 in Table 3). For the 'mild' modification level $\mathrm{T} 1$, only beech showed a small loss $(5 \%)$, while loss in OD amounted to about $12-13 \%$ with the 'intense' modification level T2 for both wood species.

Moisture conditioning led to an average $\mathrm{MC}$ in the specimen sets between 3\% (spruce, modification level T2 at moisture level ML1) and 85\% (beech, T0, ML5) with little variation within the different specimen sets except for the wet specimens at moisture level ML5 (Table 4). As expected, equilibrium wood moisture content (EMC) was clearly reduced for TMT. Within the hygroscopic range, the reduction of EMC was about $40 \%$ and $60 \%$ for modification levels $\mathrm{T} 1$ and $\mathrm{T} 2$, respectively. The reduction was similar for beech and spruce and slightly less pronounced at higher moisture levels. Water soaking for ML5 did not

Table 3 Oven-dry density of specimens at different treatment levels

\begin{tabular}{llcc}
\hline \multirow{2}{*}{$\begin{array}{l}\text { Treatment } \\
\text { level }^{\mathrm{a}}\end{array}$} & Statistics & \multicolumn{2}{l}{ Oven-dry density $\left(\mathrm{g} / \mathrm{cm}^{3}\right)$} \\
\cline { 3 - 4 } & & Wood species & \\
\cline { 3 - 4 } & & 65 & Spruce \\
\hline $\mathrm{T} 0$ & $n$ & 0.684 & 75 \\
& Mean & 0.039 & 0.402 \\
& Std & 60 & 0.056 \\
$\mathrm{~T} 1$ & $n$ & 0.652 & 75 \\
& Mean & 0.036 & 0.403 \\
& Std & 0.95 & 0.065 \\
& Ratio T1/T0 & 74 & 1.00 \\
T2 & $n$ & 0.602 & 73 \\
& Mean & 0.046 & 0.351 \\
& Std & 0.88 & 0.026 \\
& Ratio T2/T0 & & 0.87 \\
\hline
\end{tabular}

$n$ number of replicate specimens, Mean arithmetic mean, Std standard deviation, Ratio ratio of mean property value of TMT to mean value of untreated controls (T0)

Ratio values denote in italics

${ }^{\text {a }}$ See Table 1 
Table 4 Wood moisture content of specimens at different treatment and moisture levels $n$ number of replicate specimens, Mean arithmetic mean, Std standard deviation, Ratio ratio of mean property value of TMT to mean value of untreated controls (T0)

Ratio values denote in italics

${ }^{\text {a }}$ See Table 1

b See Table 2

\begin{tabular}{|c|c|c|c|c|c|c|c|}
\hline \multirow[t]{3}{*}{ Wood species } & \multirow[t]{3}{*}{ Treatment level $^{\mathrm{a}}$} & \multirow[t]{3}{*}{ Statistics } & \multicolumn{5}{|c|}{ Wood moisture content (\%) } \\
\hline & & & \multicolumn{5}{|c|}{ Moisture level $^{\mathrm{b}}$} \\
\hline & & & ML1 & ML2 & ML3 & ML4 & ML5 \\
\hline \multirow[t]{11}{*}{ Beech } & \multirow[t]{3}{*}{ T0 } & $n$ & 13 & 13 & 13 & 13 & 13 \\
\hline & & Mean & 7.50 & 11.26 & 17.98 & 25.78 & 85.97 \\
\hline & & Std & 0.09 & 0.14 & 0.50 & 1.03 & 4.96 \\
\hline & \multirow[t]{4}{*}{$\mathrm{T} 1$} & $n$ & 12 & 12 & 12 & 12 & 12 \\
\hline & & Mean & 4.89 & 7.11 & 12.57 & 18.56 & 69.68 \\
\hline & & Std & 0.09 & 0.10 & 0.16 & 0.68 & 4.68 \\
\hline & & Ratio T1/T0 & 0.65 & 0.63 & 0.70 & 0.72 & 0.81 \\
\hline & \multirow[t]{4}{*}{$\mathrm{T} 2$} & $n$ & 15 & 15 & 15 & 15 & 14 \\
\hline & & Mean & 3.28 & 4.90 & 7.33 & 9.97 & 48.16 \\
\hline & & Std & 0.12 & 0.16 & 0.28 & 0.67 & 3.70 \\
\hline & & Ratio T2/T0 & 0.44 & 0.44 & 0.41 & 0.39 & 0.56 \\
\hline \multirow[t]{11}{*}{ Spruce } & \multirow[t]{3}{*}{ T0 } & $n$ & 15 & 15 & 15 & 15 & 15 \\
\hline & & Mean & 8.41 & 12.21 & 18.08 & 26.51 & 68.70 \\
\hline & & Std & 0.23 & 0.39 & 0.31 & 0.93 & 16.88 \\
\hline & \multirow[t]{4}{*}{$\mathrm{T} 1$} & $n$ & 15 & 15 & 15 & 15 & 15 \\
\hline & & Mean & 4.93 & 6.83 & 11.68 & 17.17 & 61.84 \\
\hline & & Std & 0.52 & 0.73 & 1.10 & 2.02 & 12.59 \\
\hline & & Ratio T1/T0 & 0.59 & 0.56 & 0.65 & 0.65 & 0.90 \\
\hline & \multirow[t]{4}{*}{$\mathrm{T} 2$} & $n$ & 15 & 15 & 15 & 14 & 14 \\
\hline & & Mean & 3.51 & 5.32 & 8.23 & 12.43 & 41.34 \\
\hline & & Std & 0.16 & 0.28 & 0.30 & 0.97 & 3.90 \\
\hline & & Ratio T2/T0 & 0.42 & 0.44 & 0.46 & 0.47 & 0.60 \\
\hline
\end{tabular}

lead to fully saturated specimens, but MC was well above fibre saturation (FSP) in all cases.

General bending behaviour

A distinctly different bending behaviour of TMT as compared to untreated solid wood was apparent in the loaddeflection curves of individual specimens (Fig. 1). While untreated beech controls (T0) at standard climate (ML2) exhibited some plastic deformation after the initial linear elastic phase, thermally modified beech (T2) showed quite abrupt failures at relatively small deflections just beyond the proportional limit, connected with somewhat lower maximum loads. A high MC (ML5) basically also lowered maximum loads. However, in untreated controls an extended plastic deformation with considerably larger deflections at maximum load could be observed, but with TMT the abrupt failure behaviour remained unaffected by moisture.

The more abrupt failure behaviour of TMT was also evident in a different morphology of the transverse-fracture surfaces as seen by FE-SEM (Fig. 2). Tension-stressed broken fibres of untreated controls (T0) showed radially structured, disintegrated cell walls as a consequence of the high-deformation, comparably ductile failure behaviour. In contrast to that, broken fibres in TMT specimens (T2) frequently exhibited smooth, unstructured fracture surfaces indicating brittle failure behaviour [20]. Regarding the morphology of the fracture surfaces, the effect of thermal modification appeared to be more dominant than moisture effects in so far, that TMT specimens showed consistently smoother fracture surfaces than untreated controls irrespective of moisture condition. On the other hand, wetbroken specimens (ML5) showed only slightly more disintegrated cell walls than dry-broken specimens (ML2). Similar observations concerning the effects of load duration, moisture and thermal modification on the appearance of fracture surfaces have been reported already in earlier studies [41-44].

Variability of the bending properties in the different samples according to treatment and moisture levels was considerable but quite uniform. Average coefficients of variation within the samples were 17, 21 and $27 \%$ for MOE, MOR and DFMAX, respectively. Compared to this, variability of OD was lower with an average coefficient of variation of $10 \%$. Generally, variability of material 
Fig. 1 Examples of loaddeflection curves for individual beech specimens at two selected treatment (T0, T2, see Table 1) and moisture levels (ML2 and ML5, see Table 2). Curves for individual specimens are

slightly offset on the $x$-axis to avoid overlapping. This offset has to be taken into account for the interpretation of the absolute deflection values
Fig. 2 Examples of transversefracture surfaces of tensionbeech specimens as observed in a field-emission scanning electron microscope (FE-SEM). The selected examples correspond to the same treatment and moisture levels as in Fig. 1 (see Tables 1, 2)
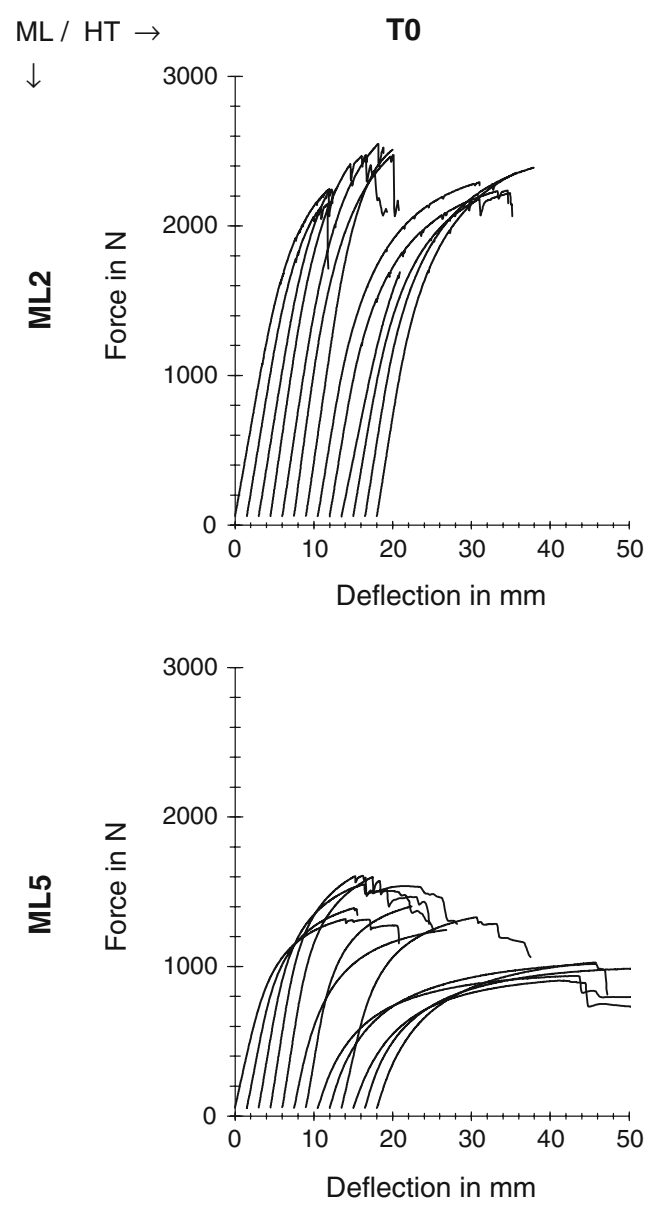

$\mathrm{ML} / \mathrm{HT} \rightarrow$

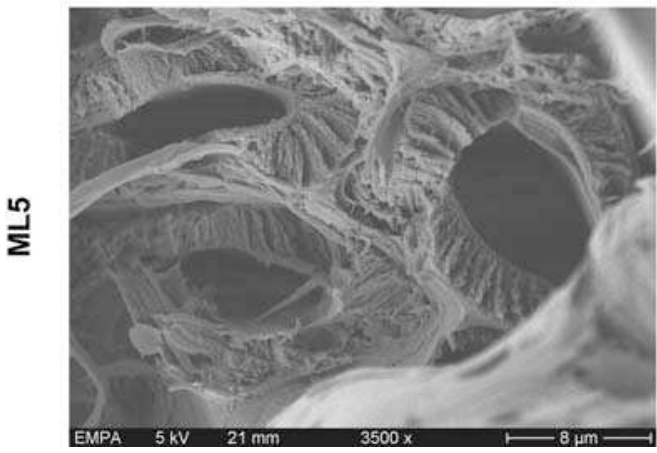

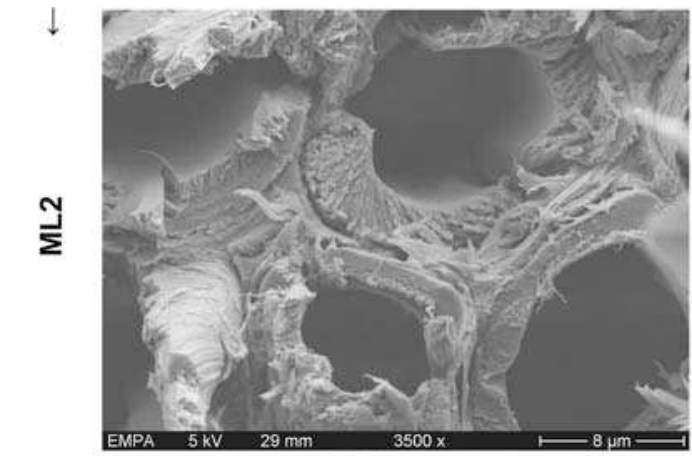

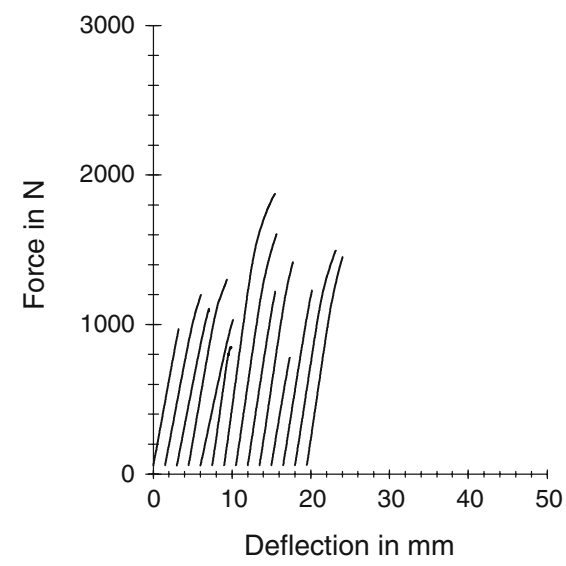

T2

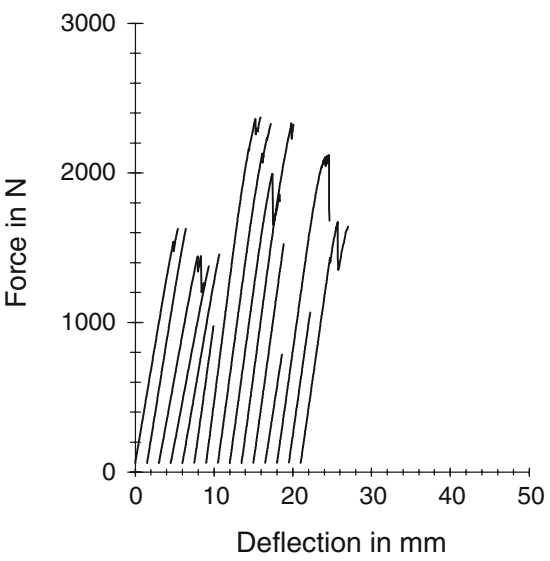

T2
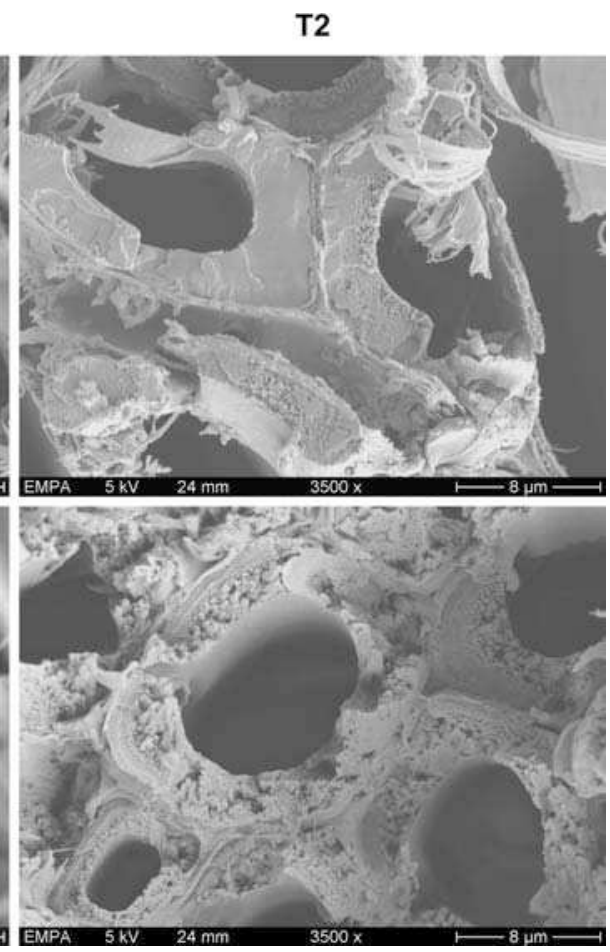
properties was lower for beech than for spruce and similar or slightly lower for TMT as compared to untreated controls.

Bending properties related to wood moisture content

In Fig. 3, the relationship between wood MC and the three selected bending properties is shown. Above fibre saturation (ML5) mechanical properties were assumed to be constant and indicated as horizontal straight lines. Below FSP (ML1 to ML4), MOE showed a quite close-fitting inverse linear dependence from MC within the explored moisture range for untreated controls as well as for TMT. For easier comparison, a linear regression was used also for
MOR, although a log-linear fit would be slightly better [17]. If mainly the MC level would have determined MOE or MOR, the values of the three treatment levels would fall on the same regression line. However, distinct shifts in property levels were present as a consequence of the changed mechanical properties due to the thermal modification. With increasing thermal modification, MOR was shifted towards lower values indicating a progressing decrease of bending strength. For MOE no clear rank order was present, pointing to a non-linear change in elasticity, with an initial increase and a decrease only after a more intense thermal modification. Despite some individual deviations, a statistical analysis (not shown) indicated identical slopes of the regression lines for the three
Fig. 3 Dependence of bending properties (MOE modulus of elasticity, MOR modulus of rupture, DFMAX deflection at maximum load) from wood moisture content (MC) at different treatment levels (HT, see Table 1). Symbols indicate average values per moisture level (see Table 2); corresponding error bars are included in Fig. 4. Above fibre saturation (ML5), average values of water soaked specimens are taken as estimates of the assumed constant property level and shown as horizontal straight lines. Below fibre saturation (ML1 to ML4), MOE and MOR are linearly interpolated, while no regression was used for DFMAX
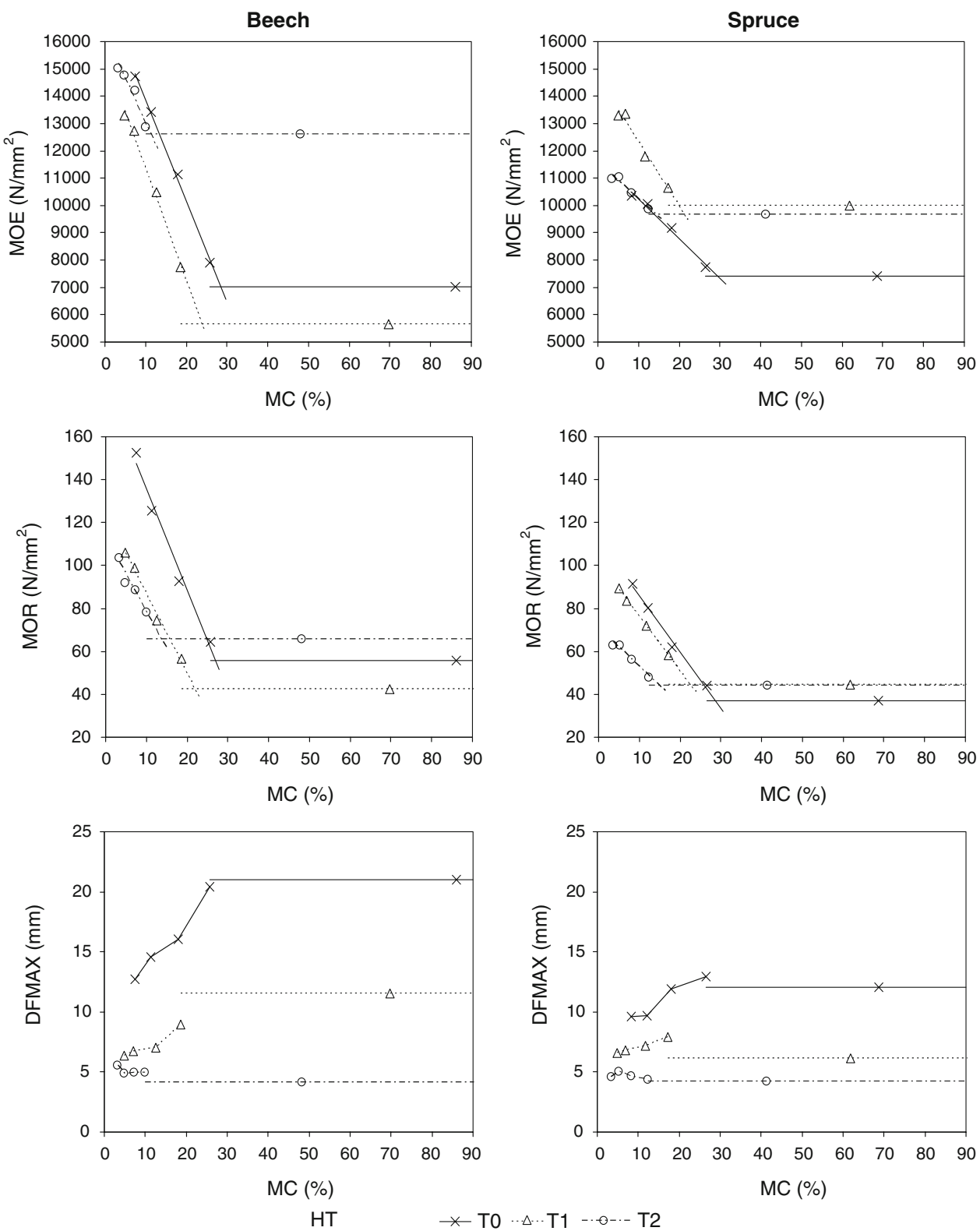
treatment levels within each property and wood species and thus, a similar dependence from MC for untreated controls and TMT.

In contrast to MOE and MOR, DFMAX increased with higher MC and probably due to a rather high variability, did not show a clear continuous dependence. Therefore, no linear regression was applied. Considerable differences of DFMAX were found between the three treatment levels. While untreated controls showed high maximum deflections increasing with MC, TMT specimens of treatment level T2 exhibited rather small deflections with very little moisture influence. Treatment level T1 was positioned in between. The decreasing maximum deflection with progressing heat treatment again indicated an increased brittleness of TMT, which at least for the high treatment level T2 appeared not to be moderated by moisture.

In general, beech and spruce behaved quite similar, but showed the expected differences in absolute property levels. Moreover, the steeper slopes of the regression lines with beech indicated a more pronounced moisture sensitivity as compared to spruce.

Bending properties related to relative humidity

An alternative interpretation of the effects of moisture on the mechanical properties is achieved by comparing the bending properties at the RH scale (Fig. 4). The relationship changed to curvilinear and showed generally more
Fig. 4 Dependence of bending properties (MOE modulus of elasticity, MOR modulus of rupture, DFMAX deflection at maximum load) from relative humidity (RH) at different treatment levels (HT, see Table 1). Symbols indicate average values per moisture level (see Table 2) with error bars showing \pm 1 standard error of mean. Symbols are slightly offset on the $x$-axis to avoid overlapping. Values for moisture level ML5 (above FSP) are positioned just beyond $100 \% \mathrm{RH}$
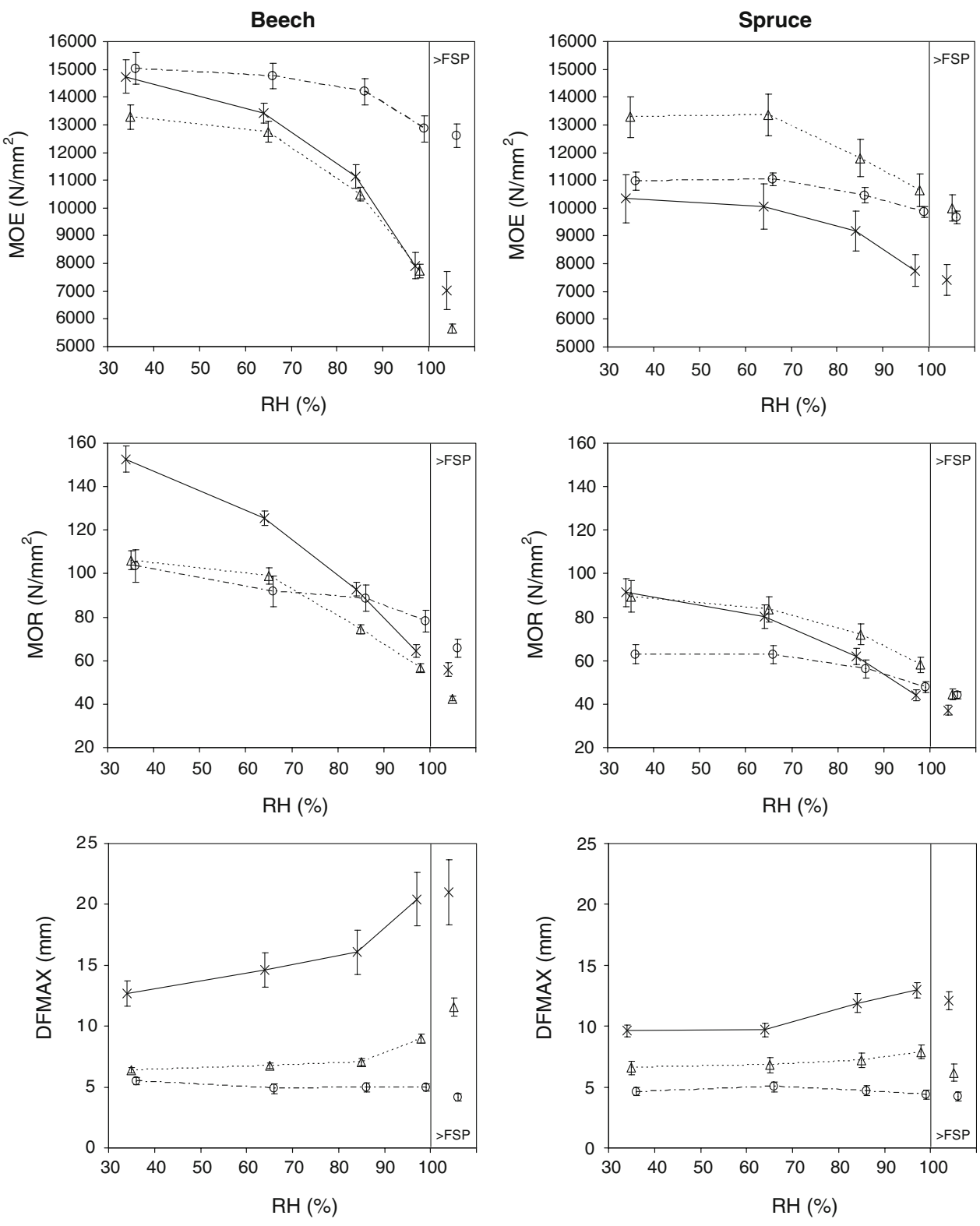
pronounced effects at higher RH. The smaller slopes of the curves for $\mathrm{T} 1$ and $\mathrm{T} 2$ indicated a reduced moisture sensitivity of TMT with a smaller change of properties related to RH. MOE and MOR reached their maximum values at low RH (30-50\% RH), while DFMAX in treatment levels T0 and T1 was highest under moist or wet conditions (ML4 or ML5, respectively).

For MOE, the rank order of the treatment levels remained the same over the explored moisture range. A thermal modification led to an increase in MOE except for beech at treatment level T1, which was not different from untreated controls. Spruce with treatment level T1 exhibited a particularly high increase in MOE. Differences in MOE between the treatment levels T0 and T2 increased with RH.

For MOR, rank order and property differences of the different treatment levels were not constant over the explored moisture range. At lower RH, untreated controls (T0) showed higher property values than TMT with treatment level T2. However, under moist or wet conditions (ML4 or ML5, respectively) the rank order was changed and T2 showed the highest values, although absolute differences between the treatment levels were small. TMT with treatment level T1 was again positioned in between.

For DFMAX, similar observations apply as with the dependence from MC in Fig. 3. Again it was apparent that a thermal modification reduced bending deflections considerably and that moisture had a plasticising effect with untreated controls, but had hardly any influence with TMT in treatment level T2. This means that TMT tended to fail with low-strain (i.e. brittle) fractures over the whole moisture range.
Relative property changes

A complementing view on the effects of thermal modification and moisture is possible by looking at the relative changes of bending properties as ratio values to untreated controls or to standard moisture conditions. In relation to untreated controls, MOE ratios of TMT fluctuated between a $20 \%$ decrease and a $79 \%$ increase depending on species, treatment and moisture level (Table 5). With treatment level T2, MOE ratios increased towards higher moisture levels. MOR ratios of TMT showed relative changes between a $32 \%$ decrease and a $32 \%$ increase. Again, increases were more pronounced at higher moisture levels. DFMAX of TMT was in all cases reduced between 30 and $80 \%$, largely independent of moisture level.

In an analogous concept to the sometimes used drygreen ratios [45], the property ratios to standard moisture conditions in Table 6 can be used to illustrate the relative effect of moisture on the bending properties. Clearly, TMT with treatment level T2 was least affected by moisture. While MOE is reduced up to $48 \%$ from standard climate (ML2) to wet conditions (ML5) for untreated controls (T0), it was reduced only about $15 \%$ with T2. MOR was affected by moisture somewhat more than MOE with a reduction of about $55 \%$ for untreated controls and $30 \%$ for T2. In the same moisture interval, DFMAX increased between $25 \%$ and $44 \%$ for untreated controls, but decreased slightly $(\sim 15 \%)$ for $\mathrm{T} 2$.

\section{Relationship between MOE and MOR}

For many practical applications, the relationship between MOE and MOR is of particular interest, since MOE is
Table 5 Ratio of bending properties of TMT to untreated controls at different treatment and moisture levels
$M O E$ modulus of elasticity, $M O R$ modulus of rupture, $D F M A X$ deflection at maximum load

${ }^{\text {a }}$ See Table $1, \mathrm{~T} 0=1.00$

b See Table 2

\begin{tabular}{|c|c|c|c|c|c|c|c|}
\hline \multirow[t]{3}{*}{ Parameter } & \multirow[t]{3}{*}{ Wood species } & \multirow[t]{3}{*}{ Treatment level $^{\mathrm{a}}$} & \multicolumn{5}{|c|}{ Ratio to treatment level $\mathrm{T}^{\mathrm{a}}$} \\
\hline & & & \multicolumn{5}{|c|}{ Moisture level $^{\mathrm{b}}$} \\
\hline & & & ML1 & ML2 & ML3 & ML4 & ML5 \\
\hline \multirow[t]{4}{*}{ MOE } & \multirow[t]{2}{*}{ Beech } & $\mathrm{T} 1$ & 0.90 & 0.95 & 0.94 & 0.98 & 0.80 \\
\hline & & $\mathrm{T} 2$ & 1.02 & 1.10 & 1.27 & 1.62 & 1.79 \\
\hline & \multirow[t]{2}{*}{ Spruce } & $\mathrm{T} 1$ & 1.28 & 1.33 & 1.29 & 1.37 & 1.35 \\
\hline & & $\mathrm{T} 2$ & 1.06 & 1.10 & 1.14 & 1.27 & 1.30 \\
\hline \multirow[t]{4}{*}{ MOR } & \multirow[t]{2}{*}{ Beech } & $\mathrm{T} 1$ & 0.70 & 0.79 & 0.80 & 0.88 & 0.76 \\
\hline & & $\mathrm{T} 2$ & 0.68 & 0.73 & 0.95 & 1.21 & 1.18 \\
\hline & \multirow[t]{2}{*}{ Spruce } & $\mathrm{T} 1$ & 0.98 & 1.04 & 1.16 & 1.32 & 1.20 \\
\hline & & $\mathrm{T} 2$ & 0.69 & 0.78 & 0.91 & 1.08 & 1.19 \\
\hline \multirow[t]{4}{*}{ DFMAX } & \multirow[t]{2}{*}{ Beech } & $\mathrm{T} 1$ & 0.50 & 0.46 & 0.44 & 0.44 & 0.55 \\
\hline & & $\mathrm{T} 2$ & 0.43 & 0.33 & 0.31 & 0.24 & 0.20 \\
\hline & \multirow[t]{2}{*}{ Spruce } & $\mathrm{T} 1$ & 0.68 & 0.70 & 0.61 & 0.61 & 0.51 \\
\hline & & $\mathrm{T} 2$ & 0.48 & 0.52 & 0.39 & 0.34 & 0.35 \\
\hline
\end{tabular}


Table 6 Ratio of bending properties at different moisture levels to standard conditions

\begin{tabular}{|c|c|c|c|c|c|c|c|}
\hline \multirow[t]{3}{*}{ Parameter } & \multirow{3}{*}{$\begin{array}{l}\text { Wood } \\
\text { species }\end{array}$} & \multirow{3}{*}{$\begin{array}{l}\text { Treatment } \\
\text { level }^{\mathrm{a}}\end{array}$} & \multicolumn{5}{|c|}{ Ratio to standard conditions (moisture level ML2) } \\
\hline & & & \multicolumn{5}{|c|}{ Moisture level $^{\mathrm{b}}$} \\
\hline & & & ML1 & $\operatorname{ML} 2^{\mathrm{c}}$ & ML3 & ML4 & ML5 \\
\hline \multirow[t]{6}{*}{ MOE } & \multirow[t]{3}{*}{ Beech } & T0 & 1.10 & $(1.00)$ & 0.83 & 0.59 & 0.52 \\
\hline & & $\mathrm{T} 1$ & 1.04 & $(1.00)$ & 0.82 & 0.61 & 0.44 \\
\hline & & $\mathrm{T} 2$ & 1.02 & $(1.00)$ & 0.96 & 0.87 & 0.85 \\
\hline & \multirow[t]{3}{*}{ Spruce } & T0 & 1.03 & $(1.00)$ & 0.91 & 0.77 & 0.74 \\
\hline & & $\mathrm{T} 1$ & 0.99 & $(1.00)$ & 0.88 & 0.80 & 0.75 \\
\hline & & $\mathrm{T} 2$ & 0.99 & $(1.00)$ & 0.95 & 0.89 & 0.88 \\
\hline \multirow[t]{6}{*}{ MOR } & \multirow[t]{3}{*}{ Beech } & T0 & 1.21 & $(1.00)$ & 0.74 & 0.51 & 0.45 \\
\hline & & $\mathrm{T} 1$ & 1.07 & $(1.00)$ & 0.75 & 0.57 & 0.43 \\
\hline & & $\mathrm{T} 2$ & 1.13 & $(1.00)$ & 0.97 & 0.85 & 0.72 \\
\hline & \multirow[t]{3}{*}{ Spruce } & T0 & 1.14 & $(1.00)$ & 0.77 & 0.55 & 0.46 \\
\hline & & $\mathrm{T} 1$ & 1.07 & $(1.00)$ & 0.86 & 0.69 & 0.53 \\
\hline & & $\mathrm{T} 2$ & 1.00 & $(1.00)$ & 0.89 & 0.76 & 0.70 \\
\hline \multirow[t]{6}{*}{ DFMAX } & \multirow[t]{3}{*}{ Beech } & T0 & 0.87 & $(1.00)$ & 1.10 & 1.40 & 1.44 \\
\hline & & $\mathrm{T} 1$ & 0.94 & $(1.00)$ & 1.04 & 1.33 & 1.71 \\
\hline & & $\mathrm{T} 2$ & 1.13 & $(1.00)$ & 1.02 & 1.02 & 0.86 \\
\hline & \multirow[t]{3}{*}{ Spruce } & T0 & 0.99 & $(1.00)$ & 1.23 & 1.34 & 1.25 \\
\hline & & $\mathrm{T} 1$ & 0.97 & $(1.00)$ & 1.06 & 1.16 & 0.91 \\
\hline & & $\mathrm{T} 2$ & 0.92 & $(1.00)$ & 0.94 & 0.87 & 0.84 \\
\hline
\end{tabular}

frequently used as an indicating property for mechanical performance and ultimate strength predictions (e.g. in machine strength grading). Concerning TMT the question was, if and how this relationship is affected by moisture (Fig. 5). Quite close-fitting linear relationships with coefficients of determinations $R^{2}$ between 0.75 and 0.97 were present with untreated controls (T0). With progressing thermal modification (T1, T2), correlations became weaker. Furthermore, a quite clear separation of the moisture levels was apparent with untreated controls, while the respective data ranges overlapped progressively with TMT, indicating a decreasing importance of moisture effects. As a result of the already observed different sensitivity of MOE and MOR on changes in moisture, the slopes of the linear regressions were generally decreasing with increasing moisture level. Except for the different separation of the moisture level groups in treatment level $\mathrm{T} 1$, beech and spruce behaved quite similar.

\section{Discussion}

The bending behaviour of TMT is determined by the combined effects of thermally induced structural changes and a lower moisture sensitivity. In the present study, bending strength at standard (dry) climate conditions was reduced by the thermal modification, while stiffness tended to show some increase. Despite differences in absolute property level, the effects of moisture on the bending behaviour of TMT was shown to be similar to untreated solid wood in so far, that bending stiffness and strength decreased considerably with increasing MC. Like in untreated solid wood, bending MOE and MOR of TMT depended approximately linearly on $\mathrm{MC}$, while related to $\mathrm{RH}$ the dependence was curvilinear. However, because of the decreased moisture sensitivity (lower EMC) of TMT, the moisture dependence of its bending properties was reduced, particularly after a more intense thermal modification. This is particularly true regarding the bending deflection of TMT, which was largely unaffected by moisture. Compared to untreated solid wood, also the failure behaviour of TMT was changed considerably. Frequently, fractures occurred abruptly and appeared brittle. Unlike in untreated solid wood, plastic deformation was not increased at higher MC and brittleness was present also in wet conditions. Finally, the relationship of stiffness and bending strength was also affected two-fold by the thermal modification. With progressing thermal modification and increasing moisture level, correlations became weaker and thus the predictive power of the material elasticity (MOE) towards ultimate strength (MOR) was reduced for TMT.

The reasons for the characteristic bending properties of TMT are, as with solid wood, ultimately linked to the chemical and structural composition of the cell wall down to the molecular level. The wood cell wall is regarded as a natural composite material formed by complex interactions 
Fig. 5 Relationship of MOE (modulus of elasticity) and MOR (modulus of rupture) at three different treatment levels (T0, T1, T2, see Table 1) and three selected moisture levels (ML1, ML3 and ML5, see Table 2). As a measure of the degree of correlation the coefficients of determination $R^{2}$ of the linear regressions are indicated for the different moisture levels
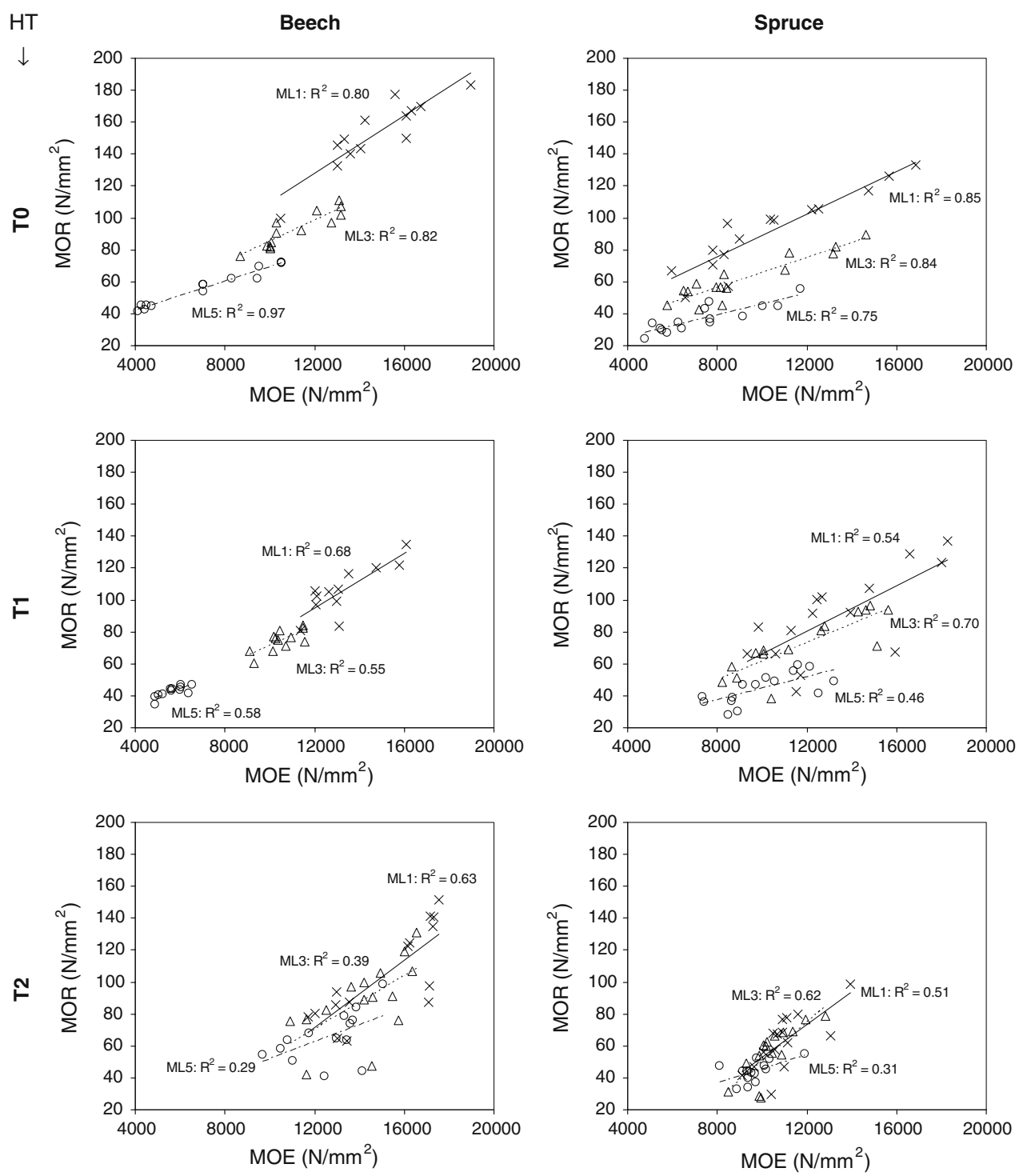

$\mathrm{ML} \quad * \begin{array}{lllll} & \cdots \Delta \cdots & -\cdots-\cdot 5\end{array}$ of its main polymers cellulose, hemicelluloses and lignin [22, 46-49]. In this composite, cellulose is seen as fibrous component determining ultimate strength, while hemicelluloses and lignin form the matrix with an important role regarding stress transfer. Moisture affects this composite in the form of bound water in the cell wall (mainly associated with the hemicelluloses), which from a mechanical perspective primarily reduces hydrogen bonding between its polymers and thus has a plasticising effect. However, as concluded in [49, 50], many chemical and mechanical aspects of the wood cell wall are still not fully understood and therefore, respective interpretations of material properties based on available theoretical and empirical evidence remain somewhat speculative.

A thermal modification initiates a complex process of polymer degradation and possible cross-linking with degradation products, which substantially changes the initial structure and interaction of the wood polymers [2-5]. Together with anatomical changes on the macro- to microscopic scale $[4,33]$, this can lead to considerable alterations of the material properties. It is generally agreed, that the decomposition of the hemicelluloses is the dominant process in a mild to moderate thermal modification, while degradation of cellulose and lignin is limited [2-5, 33, 51-54]. Changes in cellulose appear to concern mainly an increase in the relative amount of the crystalline part [2, 4]. Because of its relatively high thermal stability, the proportional content of lignin in the cell wall is increasing during a thermal modification. Nevertheless, some lignin alterations by re-polymerisation of degradation products are suspected [53, 54]. And besides the changes in the single polymers, the change in their interaction is probably 
the most important effect of a thermal modification [53]. However, as mentioned above, many details and consequences of this complex changes are yet not known.

Bending properties are quite sensitive to changes in the composition of the cell wall [47]. The dominant degradation of the hemicelluloses by a thermal modification leads to a weakening of the matrix and as a consequence, to a reduction of many mechanical properties. However, this weakening appears to be relevant only above some critical shear stress [49] and thus elasticity (MOE) is usually less affected than ultimate strength (MOR) $[2,4,5]$. Moreover, the initial increase of crystalline cellulose during thermal modification is enhancing the stiffness of the cellulose fibrils $[55,56]$, which may promote the observed increase of MOE values and compensate for the general weakening effect by the degradation of hemicelluloses. On the other hand, the increase of crystalline cellulose also contributes to the observed increased brittleness of TMT [27, 33, 53, 57].

Like regarding primary strength effects, the influence of moisture on the bending properties of TMT is mainly related to the degradation of hemicelluloses, which are the most hygroscopic cell wall polymers [22]. Again, also the increase of the crystalline cellulose may be involved. Overall, both compositional changes cause a reduction of free hydroxyl groups in the cell wall [58] and thus a lower hygroscopicity and hence a lower EMC of TMT. This leads to the observed improved performance of TMT at higher moisture levels.

The interpretation of the moisture effects depends on the reference basis [36]. Traditionally, effects of moisture on wood properties are related to MC. In many cases, this leads to straightforward and easy-to-interpret relationships, which often show linear dependencies. However, if materials with different hygroscopic behaviour have to be compared, MC relationships may be difficult to apply in practical situations since absolute MCs will differ under identical ambient conditions ( $\mathrm{RH}$ and temperature). Therefore, properties should be compared after conditioning in identical ambient conditions, with the differing EMC only used as a secondary material property. Furthermore, because of the linked effects of thermal degradation and MC on the mechanical properties, observations have to be made over the whole range of expected moisture conditions and not only at one single moisture level.

Considering the large variability between wood species and thermal modification processes, the presented results are primarily valid for the selected wood species, the tested heat treatment process and the selected properties. Moreover, the findings are based on small clear specimens without structural defects and moisture effects with structural timber may thus differ from the described behaviour. However, the comparison to other published work [33, 36,
59] shows good agreement of general trends and it is expected that high quality TMT in structural sizes would show a similar moisture behaviour.

\section{Conclusions}

In summary, the results of this study lead to the following conclusions regarding the effect of moisture on the bending properties of TMT (in comparison to untreated solid wood).

- Despite reduced strength properties at standard (dry) climate conditions, equal or even better stiffness and strength values may be expected for TMT in moist environments as a result of the decreased moisture sensitivity of TMT.

- The failure behaviour of TMT is considerably changed with frequently abrupt and brittle fractures, largely independent of moisture conditions. This characteristic has to be included in the safety considerations for potential structural applications.

- Because of the changed EMC, references to specific moisture conditions for TMT (e.g. in design codes or product standards) should generally be made related to defined ambient conditions and not to absolute levels of wood MC.

Further work for a comprehensive assessment of the effects of moisture on the mechanical properties of TMT should include investigations regarding the effect of moisture on property distributions (e.g. regarding fractile values), extend the investigations to structural timber and other mechanical properties, include creep experiments and cover the fracture behaviour at very low MCs. Such information will be needed if TMT is considered for use in structural applications.

Acknowledgements This article is based on data collected in the EU-projects 'Nanowood' (G1ST-CT-2002-50274) and 'Holiwood' (NMP2-CT-2005-011799), which were financially supported by the Swiss State Secretariat for Education and Research and the European Commission. The test material was provided by Mitteramskogler $\mathrm{GmbH}$, Gaflenz, Austria. Specimen preparation and testing was carried out by A. Fischer, D. Heer and W. Risi (Empa, Wood Laboratory, Dübendorf, Switzerland).

\section{References}

1. Lohmann U (2003) Holz-Lexikon. DRW-Verlag, LeinfeldenEchterdingen

2. Hill CAS (2006) Wood modification-chemical, thermal and other processes. Wiley, Chichester

3. Fengel D, Wegener G (1984) Wood-chemistry, ultrastructure, reactions. De Gruyter, Berlin, New York

4. Esteves BM, Pereira HM (2009) Bioresources 4:370 
5. Rowell RM, Ibach RE, McSweeny J, Nilsson T (2009) In: Proceedings of 4th European conference on wood modification, Stockholm, Sweden, p 489

6. Rapp AO (ed) (2001) Review on heat treatments of wood. BFH/ European Commission, Hamburg

7. Teischinger A, Stingl R (eds) (2002) Modifiziertes Holz: Eigenschaften und Märkte. Universität für Bodenkultur, Wien

8. Hill CAS, Jones D, Militz H, Ormondroyd GA (eds) (2007) Proceedings of 3rd European conference on wood modification, Cardiff, UK

9. Kocaefe D, Chaudhry B, Poncsak S, Bouazara M, Pichette A (2007) J Mater Sci 42:854. doi:10.1007/s10853-006-0054-3

10. Englund F, Hill CAS, Militz H, Segerholm BK (eds) (2009) Proceedings of 4th European conference on wood modification, Stockholm, Sweden

11. Arnold M (2007) In: Proceedings of 3rd European conference on wood modification, Cardiff, UK, p 161

12. Arnold M (2009) In: Proceedings of 4th European conference on wood modification, Stockholm, Sweden, p 187

13. Kollmann F, Côté WA (1968) Principles of wood science and technology. vol I. Solid wood. Springer, Berlin

14. Skaar C (1988) Wood-water relations. Springer, Berlin

15. Forest Products Laboratory (1999) Wood handbook-wood as an engineering material. Gen Tech Rep FPL-GTR-113. U.S. Department of Agriculture, Forest Service, Forest Products Laboratory, Madison, WI

16. Rowell RM (1996) In: Hon DNS (ed) Chemical modification of lignocellulosic materials. Dekker, New York, p 295

17. Wilson TRC (1932) Strength-moisture relations for wood. U.S. Department of Agriculture, Washington, DC

18. Gerhards CC (1982) Wood Fiber Sci 14:4

19. Kretschmann DE, Green DW (1996) Wood Fiber Sci 28:320

20. Dinwoodie JM (2000) Timber: its nature and behaviour. E \& FN Spon, London

21. Thelandersson S, Larsen HJ (eds) (2003) Timber engineering. Wiley, Chichester

22. Rowell RM (2005) Handbook of wood chemistry and wood composites. Taylor \& Francis, Boca Raton

23. Kollmann F, Schneider A (1963) Holz Roh Werkst 21:77

24. Pétrissans M, Gérardin P, El bakali I, Serraj M (2003) Holzforschung 57:301

25. Metsä-Kortelainen S, Antikainen T, Viitaniemi P (2006) Holz Roh Werkst 64:192

26. Rusche H (1973) Holz Roh Werkst 31:273

27. Kubojima Y, Okano T, Ohta M (2000) J Wood Sci 46:8

28. Bengtsson C, Jermer J, Brem F (2002) In: Proceedings of International Research Group on Wood Preservation, IRG 33rd annual meeting, Cardiff, Wales, Doc. No. IRG/WP 02-40242

29. Leijten AJM (2004) HERON 49:349

30. Gonzàlez-Peña MM, Hale MDC (2007) In: Proceedings of international research group on wood preservation, IRG 38th annual meeting, Jackson Lake Lodge, Wyoming, USA, Doc. No. IRG/WP 07-40367

31. Schneider A (1971) Holz Roh Werkst 29:431

32. Bekhta P, Niemz P (2003) Holzforschung 57:539

33. Boonstra MJ, Van Acker J, Tjeerdsma BF, Kegel EV (2007) Ann For Sci 64:679

34. Epmeier H, Johansson M, Kliger R, Westin M (2007) Holzforschung 61:34

35. Pfriem A, Grothe T, Wagenführ A (2007) Holz Roh Werkst 65:321

36. Borrega M, Kärenlampi PP (2008) Holz Roh Werkst 66:63

37. Mitteramskogler GmbH home page (2009) http://www.mirako.at. Accessed 22 Jan 2009

38. DIN 52186 (1978) DIN Standard. Prüfung von Holz: Biegeversuch (Testing of wood: bending test)

39. DIN 52182 (1976) DIN Standard. Prüfung von Holz: Bestimmung der Rohdichte (Testing of wood: determination of density)

40. DIN 52183 (1972) DIN Standard. Prüfung von Holz: Bestimmung des Feuchtigkeitsgehaltes (Testing of wood: determination of moisture content)

41. Sell J, Zimmermann T (1998) Holz Roh Werkst 56:365

42. Fahlén J, Salmén L (2002) Plant Biol 4:339

43. Reiterer A, Sinn G (2002) Holzforschung 56:191

44. Reiterer A, Tschegg S (2002) J Mater Sci 37:4487. doi:10.1023/ A:1020610231862

45. Green DW, Evans JW (2001) Evolution of standardized procedures for adjusting lumber properties for change in moisture content. Gen Tech Rep FPL-GTR-127. U.S. Dept. of Agriculture, Forest Service, Forest Products Laboratory, Madison, WI

46. Dinwoodie JM (1978) Phys Technol 9:185

47. Winandy JE, Lebow PK (2001) Wood Fiber Sci 33:239

48. Bergander A, Salmén L (2002) J Mater Sci 37:151. doi:10.1023/ A:1013115925679

49. Salmén L, Burgert I (2009) Holzforschung 63:121

50. Neagu RC, Gamstedt EK, Bardage SL, Lindström M (2006) Wood Mater Sci Eng 1:146

51. Tjeerdsma BF, Militz H (2005) Holz Roh Werkst 63:102

52. Placet V, Passard J, Perré P (2008) J Mater Sci 43:3210. doi: 10.1007/s10853-008-2546-9

53. Salmén L, Possler H, Stevanic JS, Stanzl-Tschegg SE (2008) Holzforschung 62:676

54. Windeisen E, Bächle H, Zimmer B, Wegener G (2009) Holzforschung 63. doi:10.1515/HF.2009.084

55. Kubojima Y, Okano T, Ohta M (1998) J Wood Sci 44:73

56. Andersson S, Serimaa R, Vaananen T, Paakkari T, Jamsa S, Viitaniemi P (2005) Holzforschung 59:422

57. Phuong LX, Shida S, Saito Y (2007) J Wood Sci 53:181

58. Phuong LX, Takayama M, Shida S, Matsumoto Y, Aoyagi T (2007) Holzforschung 61:488

59. Widmann R (2009) In: Proceedings of 4th European conference on wood modification, Stockholm, Sweden, p 379 